throughout the polymer. Furthermore, by controlling the $\mathrm{CdCl}$, concentration, particle sizes can be varied from $2 \mathrm{~nm}$ to 2 um.

So far, so good. The synthetic system of Bianconi et al. successfully amalgamates several aspects of biomineralization and shows how these factors induce regularity in the site of CdS deposition. But the real test of how good the system is rests with the level of control of crystal shape and orientation. Here, the initial results were disappointing. X-ray and electrondiffraction studies indicated that the CdS particles are noncrystalline, suggesting that the PEO matrix acts as a potent inhibitor of $\mathrm{CdS}$ crystallization at room temperature

Heating the composite film to $120^{\circ} \mathrm{C}$ for 1 hour, however, changes the amorphous material into regular cubic crystals dispersed within the polymer matrix. Interestingly, this phase transformation is influenced by the crystallinity of the polymer, as the process of direct reaction at $120^{\circ} \mathrm{C}$ of an amorphous $\mathrm{PEO} / \mathrm{CdCl}$. film with $\mathrm{S}\left(\mathrm{SiMe}_{3}\right)$, gave crystalline $\mathrm{CdS}$ of random morphology. The authors suggest that ordered aggregation of the amorphous particles induced by the breakdown of the semicrystalline matrix at $120^{\circ} \mathrm{C}$ is responsible for the regular crystal size and habit of the final product. This is an interesting speculation and one that may have biological relevance since many organized, crystalline biominerals are formed through the phase transition of amorphous precursors. Could conformation changes in biopolymer matrices induced, for example, by postdepositional crosslinking or degradation, activate these processes?

Clearly, the formation of amorphous CdS rather than an oriented crystalline phase in PEO at room temperature necessitates a re-think of the biomineralization analogy. One critical feature to be added is the generally accepted idea in biomineralization of a multicomponent organic matrix comprising structural and functional units. In the experiments described above, PEO can be considered as a structural matrix in the sense of delineating the environment for CdS nucleation and growth. Additional components that interact directly with the formation of nuclei and their subsequent growth are required. Bianconi et al. achieved this by repeating the room temperature experiments in the presence of an $\mathrm{S}\left(\mathrm{SiMe}_{\mathrm{i}}\right)$, solution containing the surfactant acrosol-OT which has a charged sulphonate headgroup. The effect is dramatic. First, crystalline CdS forms within the film. Second, the crystals have a regular cubic morphology. Third, they have the rock-salt structure commonly considered to be the high-pressure phase of CdS. And finally, and most remarkably, the single crystals are oriented with their $a$-axis perpendicular to the plane of the organic film.

What is the role of aerosol-OT in these experiments? The authors offer a tentative explanation based on recent studies of controlled crystallization under compressed Langmuir monolayers. These investigations have shown that organized assemblies of surfactant molecules can induce the oriented nucleation of amino acids"', calcium carbonate ${ }^{11}$ and ice ${ }^{12}$ at air/water interfaces. This specificity arises from geometric, stereochemical and electrostatic relationships between the charged or polar headgroups of the surfactant film and molecules or ions in the crystal surfaces of nuclei forming at the air/water interface. Similar effects may be responsible for the oriented nucleation of $\mathrm{CdS}$ in the new system: aerosol-OT molecules could be aligned within the semicrystalline $\mathrm{PEO}$ matrix by polar interactions and thereby act as organized nucleation centres for the $\{100\}$ face of CdS

This new work offers exciting prospects for materials and polymer scientists. Clearly, many other inorganic materials and crystalline polymers need to be investigated before any realistic appraisal of its technological potential can be considered. One challenge will be to increase the low volume fractions of inorganic particles generated by current batch methods of in situ crystallization. Biological systems have solved this problem through the evolution of flow processes whereby cells regulate the fluxes of ions and molecules to and from mineralization sites. Moreover, the physical and chemical status of the biomineral may itself be an important factor in optimizing its subsequent growth and form in time and space. Analogous concepts of dynamics, feedback and iteration in materials synthesis are figments of our imagination. As far as the natural world goes, there can be no doubt that even our perceived 'smart' materials remain firmly entrenched at the bottom of the class

Stephen Mann is in the School of Chemistry. University of Bath, Bath BA2 7AY, UK.

1. Reike P. C. Calvert, P. D \& Alper, M. (eds) Materia/s Synthesis Utilizing Biological Processes. Mater. Res. Soc. Symp. Proc. 174, (1990)

. Bianconi, P. A., Lin, J. \& Strzelecki, A. R. Nature 349 $315-317$ (1991)

Samata. T, The Veliger 33, 190-201(1990)

4. Sobon, C. A., Bowen, H. K., Broad, A. \& Calvert, P. D. J Mat. Sci. Lett. 6, 901-904 (1987).

5. Reich, S. \& Goldberg. E. P. J. Polym. Sci. Phys. Edn 21. $869-879$ (1983).

. Mark, J. E.. Jiang, C.-Y. \& Tang, M.Y. Macromolecules 17, 2613-2616 (1984).

. Hess, P. H. \& Parker P. H. J. appl. Polym. Sci. 10 $1915-1927$ (1966)

8. Yamamoto, T. Kubota, E., Taniguchi, A., Kubota, M \& Tominaga Y J Mater Sci Lett 5, 132-134 (1986)

Fitzaerald, E., Gadd K. F Mortimore S \& Murray. W chem. Soc. Chem. Commun. 1588-1589 (1986)

D. Landau, E. M. et al. J. Am. chem. Soc. 111, 1436-1445 (1989).

1. Mann. S. et al. Adv. Mater. 2, 257-261 (1990)

12. Gavish, M., Popovitz-Biro, R., Lahav, M. \& Leiserovitz, L. Science 250 , $973-975(1990)$

\section{Fixed air}

SYNTHETIC polymers have hosts of important uses; but they are a great nuisance once that use is over. Some can be depolymerized back to raw monomer for re-use, though this is seldom economic. Others are designed to rot or biodegrade naturally; so far these are little used. The ideal disposable polymer would depolymerize naturally and spontaneously back to a harmless gas. One candidate for this difficult role, says Daedalus, is polymeric carbon dioxide.

Many polymers, like polyesters, polycarbonates and polyanhydrides, incorporate $-\mathrm{CO}-\mathrm{O}-$ links in their backbone. Polymeric carbon dioxide, the ultimate polyester, would consist entirely of such links. But how to make it? Most polymers are made by highly subtle catalysts, often discovered only by chance. This chance, says Daedalus, may already have been seized by the vegetable kingdom.

$\mathrm{He}$ points out that the photosynthesis of atmospheric carbon dioxide, the crucial reaction in all green plants, ceases at nightfall for lack of light. Any plant that continued to absorb carbon dioxide during the night, ready for photosynthesis next day, would have a powerful advantage. Almost the only way to achieve this would be reversible polymerization of the carbon dioxide. So DREADCO botanists are studying the plants of the tropics, where light is plentiful but carbon dioxide scarce, in search of $\mathrm{CO}_{2}$-polymerizers. This botanical quest may reveal the crucial enzyme, carbon dioxide polymerase, around which an industrial catalyst can be designed. It should also yield samples of the polymer itself, for study and characterization.

"Vanishing Plastic" (as the product will be called) will need careful formulation. In water or moist air it will slowly hydrolyse, evaporating back to carbon dioxide gas. Its life could be prolonged as desired by terminating its polymer chains, and punctuating them at intervals, with suitably unreactive copolymer groups: a strategy used to stabilize the closely related acetal resins. Short-lived Vanishing Plastics will take over the wrapping and packaging markets; longer-lived ones will be formed into boxes, bottles, pens and so on. Utterly harmless and nonflammable, Vanishing Plastic will be the ultimate environmentally virtuous product. Litter-louts will toss it gaily out of car windows while farmers spread it carelessly on their fields as a combined mulch-film and carbon dioxide source for their crops. Vanishing Cloth will be ideal for nappies, tissues and cleaningwipes, while Vanishing Paper will form the world's bus tickets, posters, junk mail, office bumph, newspapers and so on - not to mention frank confessions, forged cheques and declarations of undying love.

David Jones 